\title{
КЛИНИЧЕСКИЕ НАБЛЮДЕНИЯ
}

\section{ИДИОПАТИЧЕСКАЯ ГЕНЕРАЛИЗОВАННАЯ ДИСТОНИЯ}

\author{
Альбина Раисовна Хакимова ${ }^{1,2}$, Карина Борисовна Тиморшина ${ }^{1 *}$ \\ Эдуард Закирзянович Якупов ${ }^{2,3,4}$, Наталия Анатольевна Попова \\ ${ }^{1}$ Городская клиническая больница №7, г. Казань, Россия; \\ ${ }^{2}$ Казанский государственный медицинский университет, г. Казань, Россия; \\ ${ }^{3}$ Научно-исследовательский медицинский комплекс «Ваше здоровье», г. Казань, Россия; \\ ${ }^{4}$ Образовательный иеентр «Ваше здоровье», г. Казань, Россия
}

Поступила 26.09.2016; принята в печать 24.01.2017.

Реферат

DOI: 10.17750/KMJ2017-1044

Идиопатическая генерализованная дистония - группа нейродегенеративных заболеваний, преимущественно характеризующихся дистоническим гиперкинезом (неритмичными медленными насильственными движениями в различных частях тела, которые сопровождаются своеобразным изменением мышечного тонуса и патологическими позами). Пациентка И. 54 лет поступила с разнообразными жалобами. Ведущим синдромом был экстрапирамидный, в связи с чем дифференциальную диагностику проводили с болезнью Паркинсона, мультисистемной атрофией, кортико-базальной дегенерацией и др. Диагноз «Идиопатическая генерализованная дистония в виде гиперкинезов нижних конечностей с дистонической эквинусной установкой левой стопы и экстензией большого пальца, писчего спазма» был выставлен методом исключения. Описанное в статье клиническое наблюдение иллюстрирует многообразие клинических проявлений болезни, имитирующих клиническую картину различных неврологических и психиатрических расстройств, трудности диагностического поиска и важность своевременной диагностики данного заболевания.

Ключевые слова: идиопатическая генерализованная дистония, дифференциальная диагностика.

\section{IDIOPATHIC GENERALIZED DYSTONIA}

A.R. Khakimova ${ }^{1,2}$, K.B. Timorshina ${ }^{1}$, E.Z. Yakupov ${ }^{2,3,4}$, N.A. Popova ${ }^{l}$

${ }^{\prime}$ City Clinical Hospital №7, Kazan, Russia,

${ }^{2}$ Kazan State Medical University, Kazan, Russia;

${ }^{3}$ Scientific Research Medical Complex «Your Health», Kazan, Russia;

${ }^{4}$ Educational Center «Your Health», Kazan, Russia

Idiopathic generalized dystonia is a group of neurodegenerative diseases primarily charecterized by dystonic hyperkinetic disorder (irregular slow involuntary movements of different body parts accompanied by specific muscle tone changes and pathological poses). A 54-year-old female was admitted with various complaints. The leading syndrome was extrapyramidal due to which the differential diagnosis included Parkinson's disease, multiple system atrophy, corticobasal degeneration, etc. The diagnosis of idiopathic generalized dystonia, in the form of lower extremity hyperkinesia with dystonic equinus of the left foot and hallux extension and cheirospasm, was made by a method of exclusion. The clinical case described in the article illustrates variety of clinical manifestations of the disease imitating clinical presentation of various neurological and psychiatric disorders, complexity of diagnostic search and importance of timely diagnosis of this disease.

Keywords: idiopathic generalized dystonia, differential diagnosis.

Идиопатическая генерализованная дистония - группа нейродегенеративных заболеваний, преимущественно характеризующихся дистоническим гиперкинезом (неритмичными медленными насильственными движениями в различных частях тела, которые сопровождаются своеобразным изменением мышечного тонуса и патологическими позами) $[1,2]$. Описанное в статье клиническое наблюдение иллюстрирует многообразие клинических проявлений болезни, имитирующих клиническую картину различных неврологических и психиатрических расстройств, трудности диагностического поиска и важность своевременной диагностики данного заболевания.

Пациентка И. 54 лет поступила со следующими жалобами:

- насильственное «скрючивание» пальцев и носка правой ноги, возникающее при движении, которое заставляет пациентку остановиться, но не сопровождается болью;

- ощущение интенсивного сведения в икро-

Адрес для переписки: kbtimorshina@mail.ru 1044 ножной мышце левой ноги с возникновением «болезненного комка», появляющееся во время движения или при физической нагрузке, чаще в вечернее время, продолжающееся не менее 20 мин;

- нарушение ходьбы с возникновением ощущения, что «кто-то подталкивает сзади», из-за чего пациентка периодически падает;

- слабость в правой руке, которую пациентка описывает как ощущение, что «рука будто бы не своя», «рука висит на ниточке», «не слушается», трудно пользоваться ложкой или ручкой;

- нарушение письма: «писать становится больно», «буквы стали маленькими», «буквы к концу строчки практически исчезают»;

- изменение голоса: «стал осиплым, раньше был звонким»;

- боль в поясничной области ноющего характера, без иррадиации, по визуальной аналоговой шкале 5 баллов;

- боль в тазобедренных суставах, усиливающаяся при движениях.

Пациентку 10 лет беспокоят боли в поясничной области ноющего характера (блокады и не- 
стероидные противовоспалительные средства болевой синдром не купируют). Приблизительно 7 лет назад появились изменения со стороны ног: стала ходить «будто бы на лыжах» (об этом ей сказала соседка, сама она не замечала). Тогда же пациентке стало казаться, что её «кто-то подталкивает вперёд». Через 2 года подобные ощущения в левой ноге сменились ощущением «сведения» икроножной мышцы, появились насильственные движения в правой нижней конечности: при ходьбе «скручиваются» пальцы и носок. 3 года назад присоединилась слабость в правой руке, которая выражается в том, что при письме в этой руке возникают насильственные движения.

Анамнез жизни. Родилась в срок, вторым ребёнком (есть брат). Со слов пациентки, училась «не на отлично», любимым предметом был русский язык, занималась спортом на уровне любителя: каталась на лыжах, коньках, велосипеде, занималась макраме. Со слов матери, пациентка с четвёртого класса училась в коррекционной школе и закончила восемь классов. После окончания школы работала на заводе, продолжала обучение в вечерней школе. Затем работала в больнице (младшей медицинской сестрой), в детском саду, дворником. На пенсию вышла в 2007 г. (в ответ на вопрос «почему в 45 лет вышла на пенсию» уводит разговор в сторону).

Сопутствующие заболевания. Гипертоническая болезнь II степени, риск 3. Хроническая сердечная недостаточность I, функциональный класс II. Аутоиммунный тиреоидит. Гипотиреоз.

Вредных привычек не имеет. Среди родственников, со слов матери, подобных заболеваний не было.

Данные объективного обследования. Неврологический статус. Незначительное повышение пальпебрального и назопальпебрального рефлексов, повышение мандибулярного рефлекса, лёгкая сглаженность носогубной складки справа. Чувствительность не нарушена. В пробе БарреМингаццини удерживает руки больше минуты с обеих сторон; ноги: левую - больше минуты, правую - 40 с. В пробе Фуа-Тевенара и Вестфаля правая нога медленно возвращается в исходное положение. Проприорефлексы с рук - D $\geq \mathrm{S}$, равномерно повышены; с ног - $\mathrm{D} \geq \mathrm{S}$, равномерно повышены. Наличие патологических рефлексов: Вендеровича, аналога Россолимо с обеих сторон; повышение тонуса по экстрапирамидному типу в руках и ногах справа, симптом «зубчатого колеса» в правой руке.

Обращает на себя внимание походка пациентки: изменяющаяся, шаркающая, с элементами пропульсии, наличие антепульсии, латеропульсии, при ходьбе дистония в правой ноге с эквинусной установкой стоп и экстензией большого пальца. Неярко выраженная гипомимия. Брадифрения. Микрография, при письме периодическое нарастание тонуса в мышцах указательного пальца, фиксирующих ручку (элементы писчего спазма).

Проведены тесты оценки состояния когнитивных функций: краткая шкала оценки психи- ческого статуса (MMSE - от англ. Mini-Mental State Examination) - 23 балла, Монреальская шкала оценки когнитивных функций (MOCA от англ. Montreal Cognitive Assessment) - 23 балла. При проведении более глубоких тестов с целью определения когнитивных функций отклонений выявлено не было (за исключением того, что пациентка не нашла разницы между понятиями «отец сына» и «сын отца»). Госпитальная шкала тревоги и депрессии (HADS — от англ. Hospital Anxiety and Depression Scale) 14 баллов [3].

Согласно неврологическому осмотру, необходимо выделить экстрапирамидный синдром, который включает повышенный тонус по экстрапирамидному типу, гиперкинез по типу дистонии в ноге и руке справа, гипомимию, шаркающую походку с элементами пропульсии, положительные пробы Фуа-Тевенара и Вестфаля. Жалобы на слабость в конечностях не подтвердились объективными методами исследования при неоднократной проверке.

Обратило внимание снижение когнитивных функций в стандартных тестах, при проведении более тщательных и глубоких тестов отклонений нет. При выяснении анамнеза (учёба в коррекционной школе) уточнён изначально низкий интеллект.

По результатам проведённых инструментальных и лабораторных исследований (общий анализ крови, общий анализ мочи, биохимический анализ крови, коагулограмма, электроэнцефалография, эхокардиография, цветное дуплексное сканирования брахиоцефальных артерий, цветное дуплексное сканирование нижних конечностей, игольчатая электронейромиография) значимой патологии не выявлено. По данным рентгеновской компьютерной томографии и магнитно-резонансной томографии (МРТ) головного мозга: в белом веществе теменных долей определяются единичные мелкие очаги глиоза, незначительный перивентрикулярный глиоз.

Выяснилось, что пациентка за время своего заболевания неоднократно обращалась с жалобами к неврологам. Анализируя предоставленные пациенткой документы, можно выделить закономерность: все осматривающие её врачи находили повышенный тонус по экстрапирамидному типу, выше справа, отмечали нарастание тонуса при повторных движениях (сгибание, разгибание кисти в лучезапястных суставах, проба Дойникова), положительный тест подкладной подушки, элементы писчего спазма, гиперкинез в правой ноге. Однако мышечная сила и походка описывались врачами по-разному: по данным выписок и осмотров от разных дат сила в конечностях расценивалась и как тетрапарез до 3 баллов, и как гемипарез справа до 4 баллов, походку оценивали и как шаткую, и с элементами спастичной, и как гемипаретичную.

Дифференциально-диагностический поиск оказался сложным. Ведущим синдромом в клинике заболевания пациентки И. был экстрапирамидный, в связи с чем дифференциальную 
диагностику проводили со следующими заболеваниями.

Болезнь Паркинсона. В пользу болезни Паркинсона свидетельствуют наличие гипомимии, чувства неловкости в руке, изменённый мышечный тонус, асимметрия рефлексов, монотонная речь, ходьба медленными шажками, ахейрокинез, дистимия $[2,4,5]$. Для дебюта болезни Паркинсона характерно наличие жалоб на боли в конечностях и спине, мышечные судороги [2, 4]. Однако в связи с относительно молодым возрастом, отсутствием тремора и характерной походки, наличием дистонии, отсутствием эффекта от препарата наком (леводопа 250 мг + карбидопа 25 мг), наличием строго односторонних проявлений более 3 лет это диагноз был исключён $[2,4]$.

Мультисистемная атрофия. Наличие экстрапирамидного синдрома в виде гипомимии, брадифрении, монотонной речи, изменённого мышечного тонуса (ригидности), ходьбы медленными шажками, ахейрокинеза, резистентности к препаратам леводопы, дистонии, пирамидных знаков в виде повышения пальпебральных, назопальпебрального, мандибулярного, сухожильных рефлексов привело к необходимости дифференциальной диагностики со стрионигральной дегенерацией [стриатонигральный тип мультисистемной атрофии (МСА)]. Важные особенности МСА - билатеральное возникновение паркинсонизма и быстрое прогрессирование постуральной неустойчивости, характерная походка пациентов в виде значительного затруднения в начале движения, трудности при вставании, преодолении препятствий и поворотах, застывание, что не характерно для нашей пациентки [2-4]. Также отсутствие в течение 7 лет прогрессирования заболевания в виде ухудшения походки и частоты падений, отсутствие выраженной вегетативной дисфункции позволяют усомниться в данном диагнозе [диагностические критерии MCA (Quinn N.P., 1994; Gilman S. et al., 1998)]. По данным компьютерной томографии и MPT у больных МСА выявляют атрофию мозжечка, ствола мозга, расширение IV желудочка, базальных цистерн, что не подтвердилось у пациентки И. [2, 3].

Болезнь. Гентингтона ${ }^{I}$ (БГ). Заподозрить дебют данного заболевания позволили предполагаемый когнитивный дефицит, наличие гиперкинезов и экстрапирамидного тонуса $[2,3,5]$. Для данного заболевания, как и для клинической картины пациентки И., характерны сочетание двигательных и нервно-психических расстройств, появление первых симптомов в 30-50 лет, апатия, депрессия, брадифрения [2, 3]. Однако у пациентки нет нарушений зрительно-пространственного восприятия и конструктивного праксиса, хореической (танцующей) походки. Также в пользу отсутствия данного заболевания свидетельствуют методы нейровизуализации: для БГ характер- ны расширение передних рогов желудочков по данным МРТ головного мозга, депрессия или отсутствие альфа-ритма и преобладание низкоамплитудной активности по данным электроэнцефалографии [2, 3]. БГ - наследственное заболевание с аутосомно-доминантным типом передачи, высокой пенетрантностью патологического гена, генетический дефект локализуется на коротком плече хромосомы 4, характерна экспансия тринуклеотидных повторов [4]. Пациентке И. было проведено генетическое исследование: ЦАГ-повторы в хромосоме 4 в норме.

Кортико-базальная дегенерачия (КБД). Заподозрить данное заболевание позволили характерные жалобы пациентки на правую руку. Для КБД характерен феномен «чужой конечности», когда конечность совершает целенаправленное действие независимо от желания пациента (отсутствие контроля над конечностью) [2, 3]. Однако при более детальном осмотре оказалось, что пациентка имеет полный контроль над рукой, а жалобы появляются лишь при письме или работе, требующей участия мелкой моторики. Также в пользу КБД свидетельствовало наличие дистонии фокального или сегментарного характера в конечностях, но отсутствие прогрессирования симптоматики на протяжении 7 лет, глазодвигательных нарушений, нарушений чувствительности, апраксических и речевых нарушений поставило данный диагноз под сомнение. В соответствии с критериями постановки диагноза КБД, необходимо наличие трёх из шести признаков, которых не набиралось в клинике заболевания пациентки И. [3].

Исключив данные заболевания из диагностического поиска, мы обратили внимание на дистонию. В классификации выделяют первичные и вторичные формы дистонии. Вторичная дистония может развиваться в результате детского церебрального паралича, энцефалита, черепномозговой травмы, после таламотомии, острого нарушения мозгового кровообращения, артериовенозной мальформации, при рассеянном склерозе, матаболических расстройствах, в результате приёма препаратов леводопы, нейролептиков, антиконвульсантов, препаратов спорыньи, вследствие интоксикации и др. $[1,2,4,6]$. Факторов, способствующих развитию вторичной дистонии у нашей пациентки, мы не нашли.

Первичные дистонии подразделяются на классы: «дистония плюс» (дистония с паркинсонизмом, миоклоническая дистония, пароксизмальная дистония) и первичная дистония (идиопатическая) $[1,6]$.

Дистония плюс паркинсонизм - экстрапирамидный синдром, характеризующийся неритмичными вращательными насильственными движениями в различных частях тела, вычурными изменениями мышечного тонуса и формированием патологических поз в сочета-

\footnotetext{
${ }^{1}$ Примечание редакции. Хантингтон (Huntington, George S., 1851-1916), американский врач. В русскоязычной литературе устоялось написание «Гентингтон».
} 
нии с прогрессирующим акинетико-ригидным синдромом. Выделяют две её разновидности: $\mathrm{X}$-сцепленный синдром дистония-паркинсонизм и дистония-паркинсонизм с острым началом [6].

Для дистонии-паркинсонизма с острым началом характерны внезапное появление дизартрии, дисфагии, нарастание симптоматики на протяжении нескольких часов-дней-недель, отсутствие последующего существенного прогрессирования, но острое начало не характерно для развития клинической картины данного наблюдения. К тому же на сегодняшний день описано лишь три семьи с данным заболеванием, у которых методом генетического исследования была найдена патология в локусе $19 \mathrm{q}$ [2].

Х-сцепленный синдром дистония-паркинсонизм начинается на втором-четвёртом десятилетии жизни, что отмечено для пациентки И. Он дебютирует с фокальных дистонических гиперкинезов с постепенным развитием генерализованной формы дистонии. Данное заболевание описано у аборигенов Филиппинских островов, а для постановки диагноза необходимо обнаружение патологического гена (DYT3) в перицентромерной области Х-хромосомы $[2,6]$.

Первичная дистония характеризуется выраженным фенотипическим полиморфизмом, касающимся возраста, течения, клиники и ответа на фармакологические препараты. Чаще всего заболевание начинается с нижней конечности, сначала эти симптомы непостоянны, но постепенно становятся всё более длительными. Существует определённая зависимость между возрастом, в котором данное заболевание проявило себя, и тяжестью его течения: чем позже дистония возникла, тем медленнее её течение [2]. Возможно, данными фактами можно объяснить течение заболевания пациентки И.

Выделяют две формы дистонии.

Ригидная форма - ДОФА-зависимая: мягкое прогрессирование заболевания, постепенное присоединение лёгких паркинсоноподобных симптомов; характерно ухудшение состояния пациента к вечеру; высока эффективность малых доз препаратов леводопы [2, 6]. Находясь в стационаре, пациентка продолжала получать препарат наком (леводопа 250 мг + карбидопа 25 мг), назначенный ранее, в дозе 1 таблетка 2 раза в день, но положительной динамики не было.

Дистонически-гиперкинетическая форма ДОФА-независимая. Для постановки диагноза необходимо проведение генетического картирования. Основной ген, отвечающий за развитие дистонии, - DYT1 [2,6].

Дистония стопы у нашей пациентки развивается только во время движения и включает два основных элемента: подошвенное сгибание пальцев и ротацию стопы внутрь. В литературе описано характерное постепенное развитие данного феномена: сначала пациенты испытывают неудобства при ходьбе, прихрамывание, которое обусловлено напряжением мышц стопы, и только со временем спазм становится настолько силь- ным, что вызывает характерную патологическую установку стопы [2].

Писчий спазм - один из распространённых видов дистонии. Для клинической картины писчего спазма также характерно постепенное развитие. Субъективно пациент ощущает скованность и напряжение в кисти, которые поначалу могут быть не заметны постороннему глазу. По данным литературы, есть несколько наблюдений с медленным течением данной дистонии [2].

Учитывая наличие дистонического гиперкинеза, отсутствие положительной динамики при приеме препаратов леводопы, отсутствие когнитивных нарушений, пациентке был выставлен диагноз: «Идиопатическая генерализованная дистония в виде гиперкинезов нижних конечностей с дистонической эквинусной установкой левой стопы и экстензией большого пальца, писчего спазма».

При разборе данного наблюдения хотелось обратить внимание на сложность осмотра подобных пациентов, трудности дифференциальной диагностики. Диагноз был выставлен методом исключения. Для подтверждения предполагаемого диагноза пациентке необходимо провести генетические исследования.

\section{Авторы заявляют об отсутствии конфлик-} та интересов по представленной статье.

\section{ЛИТЕРАТУРА}

1. Залялова 3.А. Современные классификации мышечных дистоний, стратегия лечения. Ж. неврол. $и$ психиатрии. 2013; 113 (3): 85-89. [Zalyalova Z.A. Current classifications of dystonia, treatment strategy. Zhurnal nevrologii i psikhiatrii. 2013; 113 (3): 85-89. (In Russ.)]

2. Шток В.Н., Иванова-Смоленская И.А., Левин О.С. Экстрапирамидные расстройства: Руководство по диагностике и лечению. М.: МЕДпресс-информ. 2002; 608 c. [Shtok V.N., Ivanova-Smolenskaya I.A., Levin O.S. Ekstrapiramidnye rasstroystva: Rukovodstvo po diagnostike $i$ lecheniyu. (Extrapiramidal disorders: guide to diagnosis and treatment.) Moscow: MEDpressinform. 2002; 608 p. (In Russ.)]

3. Яхно Н.Н., Захаров В.В., Локшина А.Б. и др. Демениии. М.: МЕДпресс-информ. 2010; 272 с. [Yakhno N.N., Zakharov V.V., Lokshina A.B. et al. Dementsii. (Dementia.) Moscow: MEDpress-inform. 2010; 272 p. (In Russ.)]

4. Левин О.С., Штульман Д.Р. Неврология. Справочник практического врача. М.: МЕДпресс-информ. 2014; 1024 c. [Levin O.S., Shtul'man D.R. Nevrologiya. Spravochnik prakticheskogo vracha. (Neurology. A physician's practical guide.) Moscow: MEDpress-inform. 2014; 1024 p. (In Russ.)]

5. Никифоров А.С., Гусев Е.И. Частная неврология. Учебное пособие. М.: ГЭОТАР-Медиа. 2008; 768 c. [Nikiforov A.S., Gusev E.I. Chastnaya nevrologiya. Uchebnoe posobie. (Private neurology. Study book.) Moscow: GEOTAR-Media. 2008; 768 p. (In Russ.)]

6. Иллариошкин С.Н., Иванова-Смоленская И.А. Дрожательные гиперкинезы. Руководство. М.: Атмосфера. 2011; 360 c. [Illarioshkin S.N., IvanovaSmolenskaya I.A. Drozhatel'nye giperkinezy. Rukovodstvo. (Tremor hyperkinetic disorders: a Physician's Guide.) Moscow: Atmosfera. 2011; 360 p. (In Russ.)] 